\title{
The rocky exhilarating journey from data to wisdom
}

\author{
Paul Kurlansky, MD
}

Every word or concept, clear as it may seem to be, has only a limited range of applicability.

—Werner Heisenberg

Administrative versus clinical databases: which is better? Yes.

Or perhaps, neither.

And why is it that we care?

Quality assessment in medicine is not a new phenomenon. Although somewhat anathema to modern medical ethics, the Code of Hammurabi over three and half millennia ago had very specific standards for physicians. The betterknown guidelines of Hippocrates and Maimonides still resonate with physicians to this day. However, the modern era of quality assessment in health care stemmed from the efforts of Florence Nightingale to apply analytical standards to the care of soldiers during the Crimean War-based on, yes, data. Similar efforts by pioneering surgeon Ernest Codman gained him the invitation to leave the medical staff of the Massachusetts General Hospital but laid the foundation for what was later to become the American College of Surgeons and the Joint Commission. When disturbing reports of the lapses in quality from the Institute of Medicine converged with the necessity to better understand the value gained for the rapidly increasing costs of medical care, the need for reliable information to assess quality became paramount. In 1986, the Healthcare Finance Administration began releasing mortality reports based on administrative data that suggested a 5-fold variation in mortality for coronary artery bypass surgery in New York State. Concerned with the validity of the data as well as the findings, the state Department of Health decided to create a patient-level clinical database that could be used to assess institutional outcomes for coronary artery bypass surgery sensitive to differences in patient acuity. ${ }^{1}$ Subsequent study documented not only the disparity between the administrative and clinical database approaches but found the registry to be more predictive of mortality. ${ }^{2}$

From the Division of Cardiac Surgery, Department of Surgery, Columbia University, New York, NY.

Received for publication May 25, 2020; revisions received June 10, 2020; accepted for publication June 14, 2020; available ahead of print June 24, 2020.

Address for reprints: Paul Kurlansky, MD, Black Building 210, 650 West 168th St,

New York, NY 10032 (E-mail: pk2245@cumc.columbia.edu).

J Thorac Cardiovasc Surg 2021;162:1166-9

$0022-5223 / \$ 36.00$

Copyright (c) 2020 by The American Association for Thoracic Surgery

https://doi.org/10.1016/j.jtcvs.2020.06.019

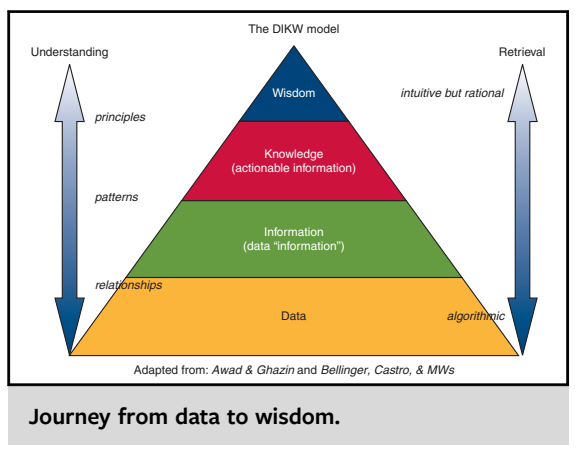

CENTRAL MESSAGE

Both clinical and administrative sources of data have an important role in quality improvement. The emerging field of data science will help to build the knowledge foundation of the future.

This Invited Expert Opinion provides a perspective on the following papers: J Am Coll Surg. 2009;209(5):551-556. https://doi.org/10.1016/j.jamcoll surg.2009.08.008; J Am Coll Surg. 2016;223(4):551557.e4. https://doi.org/10.1016/j.jamcollsurg.2016.06 393.

See Commentaries on pages 1170 and 1171.

Precedent for the clinical approach to quality improvement had already been set by the Northern New England Cardiovascular Disease Study Group which, in 1987, began collecting clinical data on cardiac surgical outcomes in a voluntary effort to identify areas for quality improvement. ${ }^{3}$ Similarly, as early as 1984 surgeons from the Society of Thoracic Surgeons (STS) began exploring the feasibility of creating a tool to facilitate comparison of outcomes. Spurred by the release of Healthcare Finance Administration data, development of a national database was approved, and by 1990 the first iteration of the STS National database was released with 50 participants.

Despite some initial challenges, the database has grown in scope, sophistication, and penetration, with more than 1000 national and international participating sites, with more than 6 million records that represent upward of $90 \%$ of the nongovernmental sites performing cardiac 
surgery in the country, and more than $95 \%$ of the patients. ${ }^{4,5}$ Careful data analytics have been applied to generate well-validated risk models for mortality and morbidity of the most commonly performed cardiac surgical operations. ${ }^{6,7}$ Although voluntary, the database is regularly audited and data related to risk models have been found to have $>95 \%$ accuracy. ${ }^{4}$ Modeling has further permitted composite ratings for both programs and surgeons, and has facilitated voluntary public reporting. Simultaneously, several states-most notably New York, New Jersey, Massachusetts, Pennsylvania, and California-maintain compulsory independent cardiac surgery reporting systems, with varying degrees of public reporting, some of which rely on STS data, some of which maintain independent data systems, and some of which combine administrative with select clinical data. In other states-Virginia, Michigan, and Washington-surgeons have formed quality collaboratives through which they share their STS data in a collective effort to drive quality improvement.

So, the issue has been settled-history has validated the superiority of the clinical database. Not so fast! Administrative data abound, and their impact are profound. Over the past decade, the National Quality Forum has endorsed more than 700 measures, many, if not most, based on administrative data. The Centers for Medicare and Medicaid Services maintains several claims databases that are not only used for reimbursement purposes but serve the basis for quality benchmarking and reimbursement decisions, such as the recently instituted and somewhatcontroversial metrics for readmissions. ${ }^{8}$ It is not surprising that administrative data are widely used-they are readily available, transmissible electronically, relatively uniform across health plans, payers, and medical institutions, and can be obtained for entire populations. Depending on the source, such data can combine the inpatient and outpatient experience, track medication usage, record costs, and link with state or national death indices to study both shortand long-term outcomes. Indeed, various national health plan databases, such those in Taiwan, ${ }^{9}$ Denmark, ${ }^{10}$ Canada ${ }^{11}$ and elsewhere, have produced clinical insights that would not have otherwise been readily obtainable.

So why the "love affair" with clinical registries? They can be labor-intensive, costly, and potentially burdensome for institutions to maintain. Indeed, the STS adult cardiac surgery database has swollen to several hundred fields, each of which requires a specific trained data manager entry. It is no surprise that many of the fields not currently incorporated into the risk models lie blank. Potentially meaningful information such as MELD (Model for End-stage Liver Disease) score of liver function and 5-meter walk test, a validated measure of frailty, are largely left blank and therefore unavailable for risk adjustment. With such a heavy burden of data entry, imagine if every medical specialty required this degree of applied resources-what hospital or health care system could sustain such an expense? And yet, especially in an area such as cardiac surgery, for which quality bears life and death consequences, and for which so much institutional resource and commitment are required to appropriately support high-level performance, one might ask what institution could afford NOT to have the ready availability of high-level clinical data.

Administrative data may simply not be up to the task. First of all, even when aggregated on a national level specifically for the purpose of studying health care, such as the Agency for Healthcare Research and Quality has done with the Healthcare Cost and Utilization Project, the data are not readily usable. Analysis has shown that $85 \%$ of published studies using the Healthcare Cost and Utilization Project's National Inpatient Sample, including those in high-impact journals, did not adhere to at least 1 or more of required methodologic practices. ${ }^{12}$ On a more granular level, statewide, ${ }^{13}$ regional, ${ }^{14}$ and individual institutional studies ${ }^{15}$ have all documented various degrees of inadequacy in institutional data. The finding of discrepancies in volume are particularly unsettling, since one might justifiably expect data amassed for billing purposes would, at very least, provide accurate information regarding the procedures performed, the date of surgery, and the hospital mortality. More careful analysis uncovered various plausible explanations-different ways of categorizing operations (isolated vs various combinations of procedures), different time frames (date of surgery vs date of discharge), different ways of categorizing patients (Medicare vs Medicare $>65$ vs Medicare Advantage, etc), and different patient groupings (adult cardiac surgery vs inclusion of adult congenital surgery). More challenging is the absence of potentially important clinical variables. Even the well-validated Charlson ${ }^{16}$ and Elixhauser ${ }^{17}$ comorbidity indices cannot capture such potentially important variables as left ventricular ejection fraction, urgency of surgery, extent of left main other coronary artery disease, degree of mitral or other valvular regurgitation, etc. Moreover, it is frequently difficult to differentiate between comorbidities that were present before surgery versus those that accrued in the postoperative period. "Present on admission" notation, where available, as well as revised codes to more clearly delineate complications have been helpful but lack the definition and distinction of well-organized clinical databases. ${ }^{18}$ Further confusion emerges from this paradigm when administrative databases such as the University HealthSystem Consortium (now Vizient), which shares data among more than 300 hospitals and represents more than $90 \%$ of the nation's nonprofit academic medical centers, develops diagnosis-related group-based risk models that achieve high discriminatory power by inclusion of postoperative events in the model- 
a potentially useful method for modeling cost but clearly inadequate for assessing performance across the spectrum of patient risk. ${ }^{19}$

Despite their more robust clinical perspective, even the most comprehensive databases such the STS are frequently not adequate for determining many subtle surgeon or hospital performance decisions that may impact major outcomes of interest (eg, what specifically drives the variability in the rate of stroke across centers or surgeons?). Moreover, most clinical databases are severely limited by their focus on perioperative events. The mere extension to the 30-day period may expose gaps in reporting when rectified with administrative data. ${ }^{20,21}$ Even though perioperative outcomes are critical for assessing quality of surgical care, more long-term data are essential to perform the vital function of determining quality in surgical decision-making: what is the impact of multiple arterial grafting? Should operative treatment of atrial fibrillation at the time of surgery be considered a metric of quality? Successful linkage of clinical and administrative data such as the STS has performed with ASCERT (ACCF and STS Database Collaboration on the Comparative Effectiveness of Revascularization Strategies) trial of coronary revascularization, as well as several other studies, are certainly a step in the right direction. ${ }^{22}$ Current initiatives to more formally link the STS with National Death Index would be a most welcome advance. Similar linkage might provide important information regarding cost, better addressing the core issue of value that is driving much of this initiative. Even with such linkage, we still will need to find ways to integrate patient perceptions of care, an emerging field that in and of itself is evolving more adept ways of capturing meaningful data.

Limitations of our current clinical databases have not gone unnoticed by the professional societies. ${ }^{23}$ Access to real-time information from the electronic medical record is an appealing prospect but will require much attention to issues of lack of electronic medical record interoperability, lack of accuracy promulgated by ubiquitous use of "copy/paste" functionality, limitations of semantic logic to translate raw and/or unstructured information into discrete clinical variables, and ever-increasing issues of data security and privacy as data are transferred across electronic networks. Despite these challenges, the emerging field of data science is providing methodologies-machine learning, neural networks, and other forms of artificial intelligence, in all of their many evolving forms to provide data-driven insights from enormous repositories of data. Already huge data warehouses such as Optum have merged administrative, clinical, and linkage streams that might not only provide the information necessary to address specific clinical questions ${ }^{24}$ but use "big-data" approaches to provide previously unanticipated data-driven insights. Such approaches have already yielded exciting insights not apparent from a hypothesis-driven approach - with the increasing demands of precision medicine, access to and linkage of such large population resources will become essential for addressing the major issues on the horizon. ${ }^{25}$

In short: clinical or administrative? Yes. And much more. Now let's get to work!

\section{Conflict of Interest Statement}

The author reported no conflicts of interest.

The Journal policy requires editors and reviewers to disclose conflicts of interest and to decline handling or reviewing manuscripts for which they may have a conflict of interest. The editors and reviewers of this article have no conflicts of interest.

\section{References}

1. Hannan EL, Cozzens K, King SB, Walford G, Shah NR. History, contributions, limitations, and lessons for future efforts to assess and publicly report healthcare outcomes. J Am Coll Cardiol. 2012;59:2309-16.

2. Hannan EL, Kilburn H, Lindsey ML, Lewis R. Clinical versus administrative data bases for CABG surgery. Does it matter? Med Care. 1992;30:892-907.

3. O'Connor GT, Plume SK, Olmstead EM. A regional prospective study of inhospital mortality associated with coronary artery bypass grafting. JAMA. 1991;266:803-9.

4. D'Agostino RS, Jacobs JP, Badhwar V, Paone G, Wormuth DW, Shahian DM The Society of Thoracic Surgeons adult cardiac surgery database: 2019 update on outcomes and quality. Ann Thorac Surg. 2019;107:24-32.

5. Jacobs JP, Shahian DM, He X, O'Brien SM, Badhwar V, Cleveland JC Jr, et al. Penetration, completeness, and representativeness of the Society of Thoracic Surgeons adult cardiac surgery database. Ann Thorac Surg. 2016;101:33-41.

6. Shahian DM, Jacobs JP, Badhwar V, Kurlansky PA, Furnary AP, Cleveland JC Jr, et al. The Society of Thoracic Surgeons 2018 adult cardiac surgery risk models: part 1-background, design considerations, and model development. Ann Thorac Surg. 2018;105:1411-8.

7. O'Brien SM, Feng L, He X, Xian Y, Jacobs JP, Badhwar V, et al. The Society of Thoracic Surgeons 2018 adult cardiac surgery risk models: part 2-statistical methods and results. Ann Thorac Surg. 2018;105:1419-28.

8. Wadhera RK, Maddox KEJ, Wasfy JH, Haneurse S, Shen C, Yeh RW. Association of the hospital readmission reduction program with mortality among Medicare beneficiaries hospitalized for heart failure, acute myocardial infarction and pneumonia. JAMA. 2018;320:2542-52.

9. Wu CK, Juang JMJ, Chiang JY, Li YH, Tsai CT, Chiang FT. The Taiwan heart registries: its influence on cardiovascular patient care. J Am Coll Cardiol. 2018;71:1273-83.

10. Christiansen MN, Køber L, Weeke P, Vasan RS, Jeppesen JL, Smith JG, et al. Age-specific trends in incidence, mortality, and comorbidities of heart failure in Denmark, 1995 to 2012. Circulation. 2017;135:1214-23.

11. Pu A, Ding L, Shin J, Price J, Skarsgard P, Wong DR, et al. Long-term outcomes of multiple arterial coronary artery bypass grafting: a population-based study of patients in British Columbia, Canada. JAMA Cardiol. 2017;2:1187-96.

12. Khera RJ, Angraal S, Souch T, Welsh JW, Nallamothu BK, Girotra S, et al. Adherence to methodological standards in research using the national inpatient sample. JAMA. 2017;318:2011-8.

13. Shahian DM, Silverstein T, Lovett AF, Wolf RE, Normand SLT. Comparison of clinical and administrative data sources for hospital coronary artery bypass graft surgery report cards. Circulation. 2007;115:1518-27.

14. Mack MJ, Herbert M, Prince S, Dewey TM. Does reporting of coronary artery bypass grafting from administrative databases accurately reflect actual clinical outcomes? J Thorac Cardiovasc Surg. 2005;129:1309-17.

15. Prasad A, Helder MR, Brown DA, Schaff HV. Understanding differences in administrative and audited patient data in cardiac surgery: comparison of the University HealthSystem Consortium and Society of Thoracic Surgeons databases. $J$ Am Coll Surg. 2016;223:551-7.e4.

16. Charlson M, Szatrowski TP, Peterson J, Gold J. Validation of a combined comorbidity index. J Clin Epidemiol. 1994;47:1245-51. 
17. Elixhauser A, Steiner C, Harris DR, Coffey RM. Comorbidity measures for use with administrative data. Med Care. 1998;36:8-27.

18. Fry DE, Pine M, Jordan H, Elixhauser A, Hoaglin DC, Jones B, et al. Combining administrative and clinical data to stratify surgical risk. Ann Surg. 2007;246: $875-85$.

19. Kozower BD. Invited commentary: administrative vs clinical data: the struggle continues. J Am Coll Surg. 2016;223:557-8.

20. Hannan EL, Samadashvili Z, Cozzens K, Chikwe J, Adams DH, Sundt TM III, et al. Out-of-hospital 30-day deaths following cardiac surgery are often under-reported. Ann Thorac Surg. 2020;110:183-8.

21. Edgerton JR, Herbert MA, Hamman BL, Ring WS. Can use of an administrative database improve accuracy of hospital-reported readmission rates? J Thorac Cardiovasc surg. 2018;155:2043-7.
22. Weintraub WS, Grau-Sepulveda MV, Weiss JM, O’Brien SM, Peterson ED Kolm P, et al. Comparative effectiveness of revascularization strategies. $N$ Engl J Med. 2012;366:1467-76.

23. Blackstone EH. A Comprehensive AATS Quality Program for the Twenty-first Century. Presented at: 99th Annual Meeting of The American Association for Thoracic Surgery, Toronto, Ontario, Canada, May 4-7, 2019.

24. Yao X, Gersh BJ, Holmes DR, Melduni RM, Johnsrud DO, Sangarlingham LR, et al. Association of surgical left atrial appendage occlusion with subsequen stroke and mortality among patients undergoing cardiac surgery. JAMA. 2018; 319:2116-26.

25. Krumholz HM. Big data and new knowledge in medicine: the thinking, training, and tools needed for a learning health system. Health Aff (Millwood). 2014;33 1163-70. 